\title{
The Study and Practice on Teaching Reform in Curriculum Group of Signal Processing Based on CDIO Mode
}

\author{
Xiaojuan Wei \\ School of Electrical Engineering \\ Northwest Minzu University \\ Lanzhou, China \\ weixiaojuan925@126.com
}

\begin{abstract}
Innovative teaching in the courses of signal processing is conducted based on the concept of CDIO engineering education. Because the signal processing courses contain many mathematic knowledge and complicated theory and logic, it is difficult for students to have sensory awareness of the courses and connect theories with engineering practice. Therefore, based on the characteristics of signal processing course and the requirements for students, this paper explores the curriculum system, course content, teaching methods, practice skills and competency assessment methods in the pattern of CDIO. It aims to arouse students' interest in signal processing courses and improve their learning effects through reform of signal processing course, so that students to have deep understanding of the content of signal processing course from the perspective of engineering.
\end{abstract}

Keywords—signal processing; CDIO; research and practice; course group

\section{INTRODUCTION}

With the rapid development of information science and technology, signal processing technology has become an important tool for China to implement the strategy of driving industrialization through informationization. The signal processing courses has become compulsory courses for many university students. However, the signal processing courses contain many mathematic knowledge and complicated theory and logic, so it is difficult for students to have sensory awareness of the course and connect theories with engineering practice. Moreover, there is less teaching reform in the signal processing curriculum system at home and abroad and less teaching research on engineering practice. Therefore, a reform is attempted to make on the signal processing curriculum system based on the CDIO engineering education concept. It is particularly important to understand, master and apply the basic principles of signal processing from the perspective of scientific research and engineering practice. Thus, it is of great value to research how to help students to understand the basic theory of signal processing from the perspective of engineering and apply it widely to scientific research and engineering practice of related disciplines.

The CDIO engineering education mode is the latest result of the international engineering education reform in recent years. It is an engineering education concept which is put forward by the four universities (such as Massachusetts Institute of Technology) since 2000 through exploration and research. CDIO stands for Conceive, Design, Implement, and Operate[1]. It takes the life cycle of product development and product operation as a tool for students to actively learn the course based on the organic connection between practice and the course. Therefore, it is important to study how to carry out teaching reform of signal processing course from the perspective of engineering application by the light of CDIO education concept. It enables students to understand the knowledge of signal processing and apply it to engineering practice, so it also guarantees better quality of engineering students and promotes the restructuring of talent cultivation. How to use the excellent engineering education mode of CDIO and how to give full play to its role in the education of undergraduates? It has become an important point in the university education in China[2].

\section{RECONSTRUCTION AND OPTIMIZATION OF CURRICULUM SYSTEM UNDER CDIO MODE}

Combined with the CDIO engineering education concept, further reconstruction of signal processing curriculum system, which includes "Signal and System", "Digital Signal Processing", "DSP Principles and Applications", and related experiments Connection should be built between different courses to set new curriculum system. For example, in the course of "Signal and System" and "Digital Signal Processing", the corresponding transformations and system characteristics of the continuous and discrete parts are different in the expression form, but they are the same in essence; building connection between different courses and learning by contrast can help students to fully understand the essence and quintessence of the theory in the signal processing course, so that they can apply the theory in engineering practice flexibly[3]. The specific content of the reform is as follows:

a)The traditional curriculum system of "Signal \& System, and "Digital Signal Processing" should be changed and a new curriculum system of "Signal \& System, Digital Signal Processing", "DSP Principles \& Applications" should be established. The fundamental and concepts should be highlighted in the "Signal and System"; the digital methods and 
technologies should be highlighted in the "Digital Signal Processing"; the realization and application of hardware and software should be highlighted in the "DSP Principles and Applications".

b) The reform should be conducted with signal analysis as the basis, system analysis as the link and digital technology as the means. Signal representation should be highlighted in the signal analysis; system description should be highlighted in system analysis. Simulation software and scientific calculation should integrated and practical examples and exercises should be added in the reform.

c) Teaching research and scientific research results should be introduced to optimize the curriculum system, and update the teaching content. Some basic content (such as DTFT, DFS and so on) in the course of "Digital Signal Processing" should be moved to the course of "Signal \& System" and engineering application cases (such as the application of fourier transform, the application of sampling theorem etc.)[4].

\section{INTEGRATION AND UPDATE OF TEACHING CONTENT}

In the curriculum system of signal processing, many theories overlap with each other, but they also have different focuses. For example, the discrete signal, discrete system, in the teaching content of "digital signal processing", discrete signals, discrete systems, Z-transformation, etc. In the course of "Digital Signal Processing" are analyzed in the course of "Signal and System". In the teaching process, no extra time should be spent on the overlapping parts, which should be taught by review and supplementary teaching to avoid simple repetition.

There is no organic integration between the course of "Signal and System" and the "Digital Signal Processing", so conclusion and integration should be conducted in the content of the two courses based on the summarization of long-term teaching experience. In the course of "Signal and System", the analysis of continuous signal and time domain and frequency domain of the system, which should be taught at the end of the course. The reason is that the course of "Digital Signal Processing" is taught immediately after the course of "Signal and System" and the course mainly focuses on the application of discrete signal and system. The course of "Signal and System" lays a theoretical foundation for the course of 'Digital Signal Processing", while the latter is the expansion and extension of the former[5]. Therefore, the teaching content of the courses is optimized through teaching reform.

Through the course of "DSP Principles and Applications", students can understand the development and application of DSP, get familiar with the basic hardware structure characteristics of DSP and DSP development environment, and learn the basic methods of DSP hardware design and software programming, laying a solid foundation for future applications and research in the field of signal processing. Therefore, in the teaching process, students can transform gradually from the software simulation of DSP algorithm to the real-time implementation with DSP processor. Firstly, MATLAB software is used for software simulation and then hybrid programming with $\mathrm{C}$ language and assembly language are used for design and debugging in the DSP integrated development environment (CCS).

\section{Reform the Practice Teaching System based on the CDIO ENGINEERING EDUCATION MODE}

The experiment and practice are a very important part in the teaching process under the CDIO mode, for students rely on this part to improve their engineering capability and comprehensive application ability.

The main feature of this curriculum system is to highlight the application of signals, so that students can master the implementation technology of signal processing. In teaching, the practice teaching system should be reformed to enhance the connection between theory and engineering practice, so that there are both theoretical system and engineering cases. Teachers should focus on the introduction of basic concepts and basic methods, introduce theories in the engineering application through theoretical derivation and enhance students' understanding of theories in the case analysis. A database of successful cases with various signals based on DSP implementation and embedded implementation should be established[6]. Therefore, in the process of teaching the basic concepts and related theories, the theoretical knowledge should be closely linked with the engineering practice, and teaching should be combined with research, so that the important application of any theory can be displayed visually to guide the scientific and technological activities of students and enable them to improve their engineering capability and practical ability. The specific reform content is as follows:

\section{A. Reform and Hierarchization of Experimental Content}

In terms of content (such as the course of "Signal and System"), in addition to the existing hardware-based experiments, more computer-based experiments based on Maltab should be added. In the course of 'Digital Signal Processing", in addition to the existing software-based experiments, more DSP-based hardware experiments should be added. In terms of design, the experiments are classified into basic verification experiments, comprehensive experiments, and design experiments, so as to meet the needs of students at different levels and to achieve multilevel integration and progressive teaching in the experiments.

\section{B. Set up Curriculum design for Signal Processing Curriculum System}

In this curriculum system, two important teaching practices should be set. One of the practices should be 'Digital Signal Processing Curriculum Design", which is the comprehensive practice of the course of 'Digital Signal Processing"; in the practice, some methods in the project teaching methods should be used for reference and students should be assigned with a task to deal with voice signal through Matlab. The other one is the "Curriculum Design of DSP Signal Processing System", which is the comprehensive integration of all the courses mentioned before; it requires students to design a real-time voice signal processing system based on DSP processor, such as the design of speech equalizer, the design of frequency analyzer of voice signal and so on, so that students can implement real-time processing of signals from the perspective 
of engineering practice. In the design of these courses, appraisal and assessment of students can guide them to carry out engineering practice activities. For example, in the latter part of the curriculum design, every student must make presentation in the form of PPT, so that they can be assessed in the aspects of oral expression, communication ability and mastery degree of technical skills. Moreover, they must complete a design report.

\section{Add Open Experimental Projects}

In the practice teaching platform, open experimental projects should be established in accordance with the requirements of the curriculum system, so as to make sure that students will make comprehensive design of this series of curriculum after class and help them to make autonomous training and improve their capability. Teachers should set up a extracurricular technical project, which is closely linked with signal processing courses, such as frequency analyzer design of sound signal, portable data acquisition and analyzer, etc. Students should divide into several groups to complete the design and production of products and write conclusion report. The open experimental projects can break down the barriers between teachers and courses and enable students to carry out research-based and exploratory learning of the engineering projects, so it is an extracurricular learning to supplement inclass learning, and an important supplementary means to guide students in engineering practice[7]. These in-class and extracurricular parts not only teaches students basic knowledge, but also help them to improve their person ability and cultivate teamwork capability, so it meets the requirements for students in the aspects of innovation activities and extracurricular practice design.

\section{TEACHING METHODS AND ABILITY ASSESSMENT METHODS}

In order to strengthen students' understanding of the theories, teachers should design animation courseware and increase the application frequency of multimedia teaching and online course in the theoretical teaching of signal processing series courses, so that the teaching process can be more interesting. Teachers should also help students to master basic concepts, theories and analytical methods, accumulate more knowledge and learn the solutions and methods to solve actual problems with theories. Relevant parties should also give full play to multimedia-aided teaching, build websites and open electronic teaching plans and examination database for free. Teachers should use online platform and examinations to enhance the communication with students and get to know students' learning situations through feedback. Improvement should be made based on the feedback of students and teachers. Meanwhile, application engineering cases can also be appropriately introduced to stimulate students' interest in learning, strengthen their understanding of knowledge, and improve students' ability to comprehensively analyze problems and solve problems. Students should be required to carry out discussion on the topic of "Signal Processing Course System in Engineering" to acquire a new understanding.

Competent assessment methods should be proposed in accordance with different course content. Teachers should focus on the process assessment of students' understanding of theories and design more practice tasks for students and assess students with mid-term examination and final examination. In addition to the knowledge taught in the course, teachers should also add some new knowledge points in the examination through randomly picking examination content in the computer database and set unified marking criteria. Course performance of students should be calculated based on their usual performance, experiment performance, mid-term examination results and final examination results, so as to urge students to study hard in every part. Since practice focuses on students' ability training, teachers should set up specific marking criteria for every project in four aspects, including basic engineering knowledge, person ability, teamwork ability and engineering system capability, which should guarantee appropriate proportion of personal ability, interpersonal competence, project design process, system construction competence and the ability to solve problems with disciplinary knowledge in the assessment, so as to form a comprehensive assessment form to reflect students' performance in the form of percentage.

\section{CONCLUSION}

This paper focuses on the introduction of CDIO education concept into teaching of signal processing courses and carries out a reform in the signal processing courses from the perspective of CDIO education concept. Students can become more proficient in the basic principles of signal processing theories through engineering application, expand their knowledge through applying the theories into scientific research and engineering practice, and improve their comprehensive abilities, including practical ability, teamwork ability, the ability to solve problems, innovative ability and so on.

\section{ACKNOWLEDGMENT}

This work is supported by Gansu Province Science Foundation for Youths(17JR5RA281), the National Natural Science Foundation of P. R. China (61463046), Fundamental Research Funds for the Central Universities of Northwest University for Nationalities of China(31920180039, 31920180120) and by the Teaching Reform Project of Northwest University for Nationalities of China .

\section{REFERENCES}

[1] S. Simon. "Book Review - Rethinking Engineering Education: The CDIO Approach,” Journal of Technology Education, vol. 26, 2015.

[2] J. Malmqvist, M. Kjellberg, “A Survey of CDIO Implementation Globally - Effects on Educational Quality," Proceedings of 11th International CDIO Conference, 2015.

[3] J.X. Zhu, Z. Zhang, C.P. Zhu, "Research on Practical Teaching Method for Digital Signal Processing Course," Research and Exploration in Laboratory, vol. 33, pp. 180-183, 2014.

[4] Q.S. Wang, H.B. Yuan, “Teaching Probe and Practice to Digital Signal Processing,”Journal of EEE, vol. 30, pp. 87-89, 2008.

[5] Y. Luo, "Research and Practice of Integration of Two Courses "Signals and Systems" and "Digital Signal Processing"," Journal of Jishou University, vol. 32, pp. 117-119, 2011.

[6] Y.F. Wang, J.Y. Zhang, "Construction of a Experimental Teaching System in the Curriculum Group of Signal Processing," Research \& Exploration in Laboratory, vol. 32, pp. 132 - 134, 2013.

[7] Q.Y. Zeng, J.P. Jiang, L.J. Wang, "Project Management in Signal Processing Project based on CDIO Model," Proceedings of 11th International CDIO Conference, 2015. 